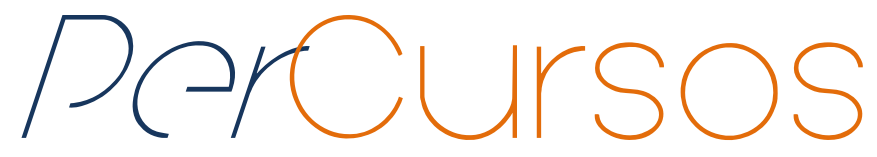

\title{
O movimento por justiça global - resistência aos modelos econômicos de globalização ${ }^{1}$
}

\begin{abstract}
Resumo
Britta Baumgarten oferece uma visão geral do Movimento por Justiça Global (MJG) e seus precursores. Distingue diferentes fases do desenvolvimento do movimento, delineia a crítica que o movimento faz aos modelos dominantes de globalização econômica, as formas de protesto favorecidas pelo movimento e traça uma descrição dos seus principais atores e suas principais áreas geográficas. Seu artigo ainda avalia o impacto e os resultados do movimento. Ela argumenta que o MJG é difícil de definir por causa de suas fronteiras imprecisas e da sua diversidade interna. Os primórdios do movimento e o seu nome são debatidos entre os estudiosos dos movimentos sociais e nem sempre está claro quem pertence ao movimento e quem não. Neste sentido, Baumgarten sublinha as conexões, as semelhanças e as diferenças entre o Movimento por Justiça Global e os movimentos Occupy e Indignados dos anos 2011 e 2012. Embora algumas reivindicações e práticas sejam semelhantes, a estrutura organizacional dos protestos atuais diversifica, e as estruturas de cooperação existentes praticamente não foram empregadas pelos novos movimentos em seu início. Ademais, as suas reivindicações são predominantemente voltadas para os governos nacionais. Assim, embora os movimentos tenham muito em comum com o MJG, eles não podem ser considerados como parte do Movimento por Justiça Global.
\end{abstract}

Palavras-chave: Movimento por Justiça Global. Movimentos sociais transnacionais. Fóruns Sociais. Indignados. Occupy.

\author{
Britta Baumgarten \\ Cies LISBOA \\ britta.baumgarten@gmail.com \\ Tradução \\ Fernando Coelho \\ Mestre em Estudos da Tradução \\ e doutorando em Linguística na \\ Universidade Federal de Santa \\ Catarina \\ zeffiretto@gmail.com
}

\section{Para citar este artigo:}

BAUMGARTEN, Brita. O movimento por justiça global - resistência aos modelos econômicos de globalização. Revista PerCursos, Florianópolis, v. 14, n.2. jul./dez. , 2013. p. 324 - 359.

\section{DOI: $10.5965 / 1984724614272013324$}

http: //dx.doi.org/10.5965/1984724614272013324

\footnotetext{
${ }^{1} \mathrm{O}$ texto original está no prelo e será publicado ainda no ano de 2014 no livro: Stefan Berger and Holger Nehring (forthcoming) Global Social Movements, Basingstoke: Palgrave Macmillan.
} 


\title{
The global justice Movement
}

\section{- resistence to dominant}

economic models of

globalization.

\begin{abstract}
Britta Baumgarten gives an overview over the global justice movement (GJM) and its forerunners. It distinguishes different phases of the development of the movement, outlines the movement's critique of dominant models of economic globalization, forms of protest favored by the movement and offers a description of its key actors and key geographical areas. Her article further evaluates the movement's impact and outcomes. She argues that the GJM is difficult to define because of blurred borders and internal diversity. The beginnings of the movement and its name are debated amongst social movement scholars and it is not always clear who belongs to the movement and who does not. In this sense Baumgarten highlights connections, similarities and differences between the global justice movement and Occupy and Indignados movements of the years 2011 and 2012. Although some claims and practices are similar, the organizational structure of the current protests differs and the existing structures of cooperation were practically not used by the new movements in their beginning. Furthermore their claims are predominantly directed towards national governments. Thus although the movements have a lot in common with the GJM, they cannot be regarded as a part of the global justice movement.
\end{abstract}

Keywords: Global justice movement.

Transnational social movements. Social Forums. Indignados. Occupy. 


\section{Introdução}

A resistência aos modelos econômicos de globalização dominantes tem uma longa história, abarcando vários movimentos, protestos e campanhas, como, por exemplo, a rebelião de Túpac Amaru II (1780/1781), ou o movimento de comércio antiescravagista (que teve o seu ápice em 1787 e 1907). ${ }^{2}$ Este artigo tem como foco uma das suas mais recentes encarnações: o "movimento por justiça global” (MJG). As recentes mobilizações dos movimentos Indignados e Occupy não fazem parte deste movimento. Estes movimentos atuais entraram em cena em 2011 e tornaram-se relevantes porque os seus grandes protestos de rua e as ocupações de espaços públicos estão voltados para os seus respectivos governos nacionais, clamando por democracia e contra programas de austeridade. Segundo Dieter Rucht, "um movimento social pode ser definido como uma rede de indivíduos, grupos e organizações que, baseados no sentimento de identidade coletiva, buscam levar a efeito mudanças sociais (ou resistir a mudanças sociais), sobretudo por meio de protestos públicos coletivos."3 A fim de falar sobre um movimento como uma entidade, é preciso que haja certo grau de consenso sobre o que os ativistas percebem como um motivo de queixa e como os problemas e as soluções são definidos. Os atores de um movimento também precisam estar relacionados uns com os outros, pelo menos no sentido de eles considerarem as suas lutas relacionadas. Similaridades nas formas de ação e práticas internas também precisam existir de modo significativo, para que os observadores possam falar sobre os movimentos. Estes critérios também são importantes quando temos de decidir se consideramos um movimento como um novo movimento ou como a continuidade de um movimento pré-existente. Conquanto algumas reivindicações e práticas sejam muito similares às do MJG, a estrutura organizacional dos presentes protestos difere, e as conexões internacionais do MJG quase não são usadas por estes novos movimentos. Uma vez que as presentes mobilizações têm muito em comum com o Movimento por Justiça Global, e como já existe pesquisa comparativa sobre estes movimentos que revela as continuidades entre o

\footnotetext{
${ }^{2}$ Heckscher, Z. (2002) 'Long before Seattle. Historical Resistance to Economic Globalization' in R. Broad (ed.) Global Backlash. Citizen Initiatives for a Just World Economy (Lanham: Rowman \& Littlefield).

${ }^{3}$ Rucht, D. 'Social Movements. Some conceptual challenges'.
} 
MJG e as presentes mobilizações, ${ }^{4}$ este artigo irá ocasionalmente enfatizar as conexões, as similaridades, assim como as diferenças e as descontinuidades entre esses movimentos. Não é fácil definir o Movimento por Justiça Global: sua diversidade e o seu escopo global resistem a qualquer classificação simplista. Os pesquisadores discutem se o rótulo do que eu chamo aqui de "Movimento por Justiça Global” é apropriado. Na literatura encontramos também os termos "movimento não-global”, "movimento antiglobalização”, "movimento alter-globalização", ou “movimento por globalização alternativa" e "movimento para a globalização partindo de baixo". Estes termos são contestados porque há um desacordo sobre os principais objetivos do movimento. Estes foram descritos como "anticapitalistas", "anticorporativistas", ou "antiglobalização". 5 À luz da grande diversidade de atores e finalidades, alguns autores falam de movimentos de justiça global no plural. ${ }^{6}$ A grande variedade de rótulos ilustra as dificuldades da pesquisa em ciências sociais para classificar o MJG. ${ }^{7}$ Diante da mesma dificuldade, os rótulos para as mobilizações atuais são criados em termos amplos, tais como "Indignados" (em alusão ao ensaio de Stéphane Hessels "Indignez-vous" ${ }^{8}$ ), "Occupy" (em alusão a formas de ação) ou “Primavera Árabe” (em alusão a regiões). É igualmente preciso ter presente que os próprios ativistas rotulam os seus eventos de modo todo-compreensivo. Por exemplo, 15M foi escolhido como o nome para a ocupação de Puerta del Sol, em Madri, em alusão apenas à data do evento (15 de maio de 2011), e de forma similar os protestos mundiais 150 (15 de outubro de 2011). ${ }^{9}$

\footnotetext{
${ }^{4}$ Hayduk, R. (2012) 'Global Justice and OWS. Movement Connections', Socialism and Democracy, 26, 2, 4350. Romanos, E. (2013) 'Collective Learning Processes within Social Movements. Some Insights into the Spanish 15M/Indignados Movement' in C. Flesher Fominaya, L. Cox (eds.) Understanding European Movements. New Social Movements, Global Justice Struggles (New Yourk/ Oxford: Routhledge).

${ }^{5}$ Giugni, M., Bandler Marko and Nina Eggert (2006) The Global Justice Movement. How Far Does the Classic Social Movement Agenda Go in Explaining Transnational Contention?, data de acesso: 27 de Agosto de 2009 (aqui 2). Ibrahim, Y. (2009) 'Understanding the Alternative Globalisation Movement', Sociology Compass, 3, 3, 394-416 (aqui 397).

${ }^{6}$ Brand, U. 'Contradictions and crises of neoliberal-imperial globalization and the political opportunity structures for the Global Justice Movements', Innovation: The European Journal of Social Science Research, 25, 3 (2012), 283-298. Rucht, D. (2011) 'Social Forums as Public Stage and Infrastructure of Global Justice Movements' in J. Smith, S. Byrd, E. Reese, E. Smythe (eds.) Handbook on World Social Forum Activism (Boulder, CO: Paradigm Publishers).

7 Bringel, B. and E. Muñoz (2010) 'Dez anos de Seattle, o movimento antiglobalização e a ação coletiva transnacional', Ciências Sociais Unisinos, 46, 1, 28-36 (aqui 30).

${ }^{8}$ Hessel, S. and M. Duvert (2011) Time for outrage! (New York: Twelve).

${ }^{9}$ Baumgarten, Britta 'Geração à Rasca and Beyond. Mobilizations in Portugal after 12 March 2011', Current
} 
Um dos principais slogans do MJG é "unidade na diversidade", que indica uma identidade comum e a valorização de diferenças internas dentro do movimento. O MJG consiste em vários atores ao redor do mundo, incluindo ONGs, organizações de pessoas comuns, partidos políticos e indivíduos. Durante o seu tempo de existência, lançou diversas campanhas, desde o alívio de dívidas em relação à taxa Tobin, até questões ambientais. A descrição "movimento de movimentos" ${ }^{10}$ cai bem ao MJG, porquanto muitos movimentos, como movimentos ecológicos, de mulheres ou indígenas, desempenharam um papel importante no MJG. Com efeito, muitos grupos de ativistas que desempenharam um papel em outros movimentos sociais também fizeram parte do MJG, embora a parte principal de suas atividades não esteve ligada a ele. O Movimento por Justiça Global se desenvolveu a partir de uma grande variedade de movimentos anteriores e compartilha a maior parte de suas reivindicações e valores. Breno Bringel desenvolveu cinco características do MJG, não obstante a sua diversidade: 1) o caráter espetacular de muitas de suas formas de ação; 2) seu uso de tecnologias de comunicação baseadas na Internet; 3) sua estrutura horizontal de tomada de decisão que acompanha uma estrutura decentralizada à maneira de rede; 4) o princípio do “pense global, aja local"; e 5) as reinvindicações radicais do movimento contra os modelos socioeconômicos prevalentes. Ele une vários setores da Esquerda política e social e usa o saliente slogan “Outro mundo é possível”, para opor-se ao frequentemente repetido refrão de Margaret Thatcher "Não há alternativa." "11 O que é novo acerca do movimento desde os anos 1990 é uma cooperação mais densa e a orientação de eventos para grandes encontros internacionais da elite política e econômica. O movimento se tornou publicamente visível em contraprotestos e no Processo Fórum Social: eventos ao redor dos quais a cooperação internacional interior ao movimento está estruturada. "Muitos dos mais visíveis ajuntamentos da sociedade civil estiveram explicitamente, e com frequência

Sociology, (2013), 61, 4, July (forthcoming). Tejerina, B. and I. Perrugorra (2012) 'Continuities and Discontinuities in Recent Social Mobilizations. From New Social Movements to the Alter-Global Mobilizations and the $15 \mathrm{M}^{\prime}$ in B. Tejerina, I. Perrugorra (eds.) From Social to Political. New Forms of Mobilization and Democratization, (Bilbao: Bizkaia Aretoa), 89-107.

${ }^{10}$ Giugni, M., Bandler Marko and Nina Eggert, 2006.

${ }^{11}$ Bringel, B. and E. Muñoz, 2010 (aqui 30). Pleyers, G. (2010) Alter-globalization. Becoming actors in the global age (Cambridge: Polity). 
antagonisticamente, ligados a eventos da elite global”. ${ }^{12}$ O Processo Fórum Social consiste em vários encontros internacionais de grandes proporções de ativistas que se encontram para debater alternativas ao atual sistema econômico e político, parar formar uma rede e para protestar conjuntamente contra este sistema. Uma importante questão de definição que tem um impacto no funcionamento do Processo Fórum Social permanece sem solução, contudo: “é um evento ou um movimento?”.13

A seguir descreverei o MJG com mais detalhes, levando em consideração as forças condutoras para este tipo de ativismo e os principais conflitos. Ademais, traçarei o perfil dos atores, suas formas de ação, debates e estruturação. Os principais eventos do movimento serão descritos numa perspectiva cronológica e geográfica.

\section{O Desenvolvimento do MJG em diferentes fases}

Não há consenso sobre quando o Movimento por Justiça Global realmente começou. "Muitos dizem que iniciou em Seattle. Outros afirmam que começou há quinhentos anos, quando os colonizadores disseram pela primeira vez aos povos indígenas que eles teriam de fazer as coisas de modo diferente se eles quisessem 'desenvolver-se' ou estar aptos ao ‘comércio'. Outros argumentam que o movimento começou no dia $1^{\circ}$ de janeiro de 1994, quando os Zapatistas lançaram o seu levante com as palavras 'Ya basta!' nas noites em que o Tratado Norte-Americano de Livre Comércio (NAFTA) se tornou lei no México. Tudo depende da pessoa a quem você pergunta."14

A resistência contra a globalização econômica, contudo, existe há vários séculos. ${ }^{15}$ Por exemplo, Zahara Heckscher menciona os casos do levante de Túpac Amaru II (1780/81), o movimento de comércio antiescravagista (que teve o seu ápice entre 1787 e 1807), a campanha contra a colonização do Congo, a Primeira Associação Internacional

\footnotetext{
${ }^{12}$ Teivanen, T. (2002) 'The World Social Forum and Global Democratisation. Learning from Porto Allegre', Third World Quarterly, 23, 4, 621-632 (aqui 622).

${ }^{13}$ Scerri, A. (2012) 'The World Social Forum. Another World Might Be Possible', Social Movement Studies, 1-10 (aqui 6).

14 Klein, N. (2011) 'Reclaiming the Commons' in L. Reydams (ed.) Global activism reader (New York: Continuum) (aqui 341).

${ }^{15}$ Giugni, Bandler and Eggert, 2006 (aqui 4). Broad, R., 'The Historical context' in idem (ed.) Global Backlash. Citizen Initiatives for a Just World Economy (Lanham, MS: Rowman \& Littlefield, 2002), 65-76
} 
dos trabalhadores (fundada em 1866) e o movimento anti-imperialista. ${ }^{16}$ Estes exemplos estão ligados ao MJG de hoje, mas não eram parte do movimento. Eram campanhas e movimentos com uma só causa. E embora se possa encontrar organização e protesto com uma perspectiva global, o grau de globalização era muito menor do que os movimentos de hoje.

Segundo Elizabeth Smythe, o estabelecimento de acordos de livre comércio entre as Américas e a Ásia constituiu um ponto de partida para que o movimento se tornasse global. Por exemplo, em 1985, o Canadá e os EUA assinaram um acordo de livre comércio, seguido por um acordo de livre comércio trilateral com o México em $1991 .{ }^{17}$ Os protestos contracúpulas começaram mais ou menos ao mesmo tempo em que os protestos de "fora das portas fechadas das tomadas de decisão intergovernamentais sobre assuntos globais". ${ }^{18}$ Nesta primeira fase, os ativistas lutaram pelo acesso a organizações intergovernamentais. ${ }^{19}$

O ativismo dos anos 1990 estava intimamente ligado à esperança de que várias nações unidas ajudariam a solucionar os problemas globais que os movimentos procuravam enfrentar. Exemplos incluem conferências das Nações Unidas sobre o meio ambiente e o desenvolvimento em 1992, sobre direitos humanos em 1993, sobre população em 1994, sobre o desenvolvimento social em 1995, e sobre a habitação em 1997. Neste período, os movimentos argumentaram em favor de acordos multilaterais de reforço e de mecanismos regulatórios; eles objetivavam aumentar a atenção para preocupações sociais, estabelecer regimes de informação e defender e expandir o acesso a espaços globais. ${ }^{20}$ Nesses anos, as primeiras redes contra o mercado livre começaram a atuar, as quais são importantes para o posterior processo FSM. Houve, por exemplo, a associação europeia dos fazendeiros, a Aliança Social Hemisférica (ASH) ou o Fórum

\footnotetext{
${ }^{16}$ Heckscher, 2002.

17 Smythe, E. (2011) 'Our World is not for Sale! The WSF Process and Transnational Resistance to International Trade Agreements' in J. Smith, S. Byrd, E. Reese, E. Smythe (Ed.) Handbook on World Social Forum Activism (Boulder, CO: Paradigm Publishers) (aqui 168).

${ }^{18}$ Pianta, M., F. S. Silva and D. Zola (2004) 'Global Civil Society Events. Parallel Summits, Social Fora, Global Days of Action (Update)' in H. Anheier, M. Glasius, M. Kaldor (Ed.) Global Civil Society 2004/5 (London: Sage) (aqui 2).

${ }^{19}$ Smith, J. (2008) Social movements for global democracy (Baltimore: Johns Hopkins University Press) (aqui 97).

${ }^{20}$ Smith, 2008 (aqui 95-97).
} 
Internacional sobre Globalização (FIG), 1993. ${ }^{21}$ Essas primeiras redes contra o comércio livre mantiveram encontros internacionais muito antes do primeiro Fórum Social Mundial, por exemplo, o encontro para formar o Fórum Internacional sobre Globalização (FIG) em 1994, o “encontro pela Humanidade e Contra o Neoliberalismo" dos Zapatistas de 1996, os encontros que seguiram o seu exemplo na Espanha (1997) e no Brasil (1999). ${ }^{22}$ A Ação Global dos Povos (AGP), "uma rede criada para facilitar a organização através das fronteiras, desenvolveu-se a partir de um encontro em 1998 em Genebra, com mais de 400 representantes de organizações de base de ONGs de 71 países.” ${ }^{23}$ As práticas dos ativistas contemporâneos do Norte, como parte do AGM, a certos respeitos, emanaram dos Zapatistas no Sul, um movimento que se tornou publicamente visível em janeiro de 1994, quando o NAFTA entrou em vigor. ${ }^{24}$ Neste período acontece também a festa do quinquagésimo aniversário do BM/FMI, que deu ocasião à campanha Cinquenta Anos é o Bastante. $^{25}$

Os marcos do movimento foram as cúpulas do G8, do FMI, da OMC. O MJG esteve presente (e as interrompeu ou influenciou em vários graus) nas cúpulas de Birmingham em 1998, de Seattle em 1999, de Praga em 2000 e de Gênova em 2001. Cada um desses eventos foi acompanhado por uma série de eventos e protestos periféricos. ${ }^{26}$ O quadro 1 mostra um panorama dos maiores eventos relacionados ao MJG (eventos com mais de 50.000 participantes estão marcados em cinza e os com mais de 100.000 estão marcados em cinza escuro)

\footnotetext{
${ }^{21}$ Smythe, 2011 (aqui 168). Smith, 2008 (aqui 100-101).

${ }^{22}$ Paczynska, A. (2008) 'Turtles, Puppets and Pink Ladies. the Global Justice Movement in a Post-9/11 World' Working Papers in Global Studies: No.1, August (aqui 4). Rucht, 2011 (aqui 13).

${ }^{23}$ Hayduk, 2012 (aqui 45).

${ }^{24}$ Ibrahim, 2009 (aqui 395).

${ }^{25}$ Smith, 2008 (aqui 100-101).

${ }^{26}$ Green, D. and M. Griffith (2002) 'Globalization and Its Discontents', International Affairs,78, 1, 49-68 (aqui 53).
} 
Quadro 1

\begin{tabular}{|c|c|c|}
\hline Ano & Evento & $\begin{array}{l}\text { Número de } \\
\text { Participantes }\end{array}$ \\
\hline 1996 & $\begin{array}{l}\text { Encontro Intercontinental pela } \\
\text { Humanidade e Contra o Neoliberalismo, } \\
\text { Chiapas }\end{array}$ & 3.000 \\
\hline 1998 & G8, Birmingham & $70.000^{*}$ \\
\hline 1998 & OMC, Genebra & $2.000-3.000$ \\
\hline 1998 & BM/FMI, Washington & $200-300$ \\
\hline 1999 & OMC, Seattle & 70.000 \\
\hline 1999 & WB/IMF, Washington & 1.000 \\
\hline 1999 & G8, Berlim & $800-1.000$ \\
\hline 2000 & BM/FMI, Washington & $10.000^{7.000-}$ \\
\hline 2000 & BM/FMI, Praga & $15.000^{10.000-}$ \\
\hline 2000 & G8, Okinawa & 70.000 \\
\hline 2001 & FSM, Porto Alegre & $\begin{array}{l}20.000- \\
30.000\end{array}$ \\
\hline 2001 & OMC, Doha & 1.000 \\
\hline 2001 & G8, Gênova & $\begin{array}{l}100.000- \\
250.000\end{array}$ \\
\hline 2002 & FSM, Porto Alegre & $\begin{array}{c}40.000- \\
60.000\left(150.000^{a}\right)\end{array}$ \\
\hline
\end{tabular}




\begin{tabular}{|c|c|c|}
\hline 2002 & FSE, Florence & 60.000 \\
\hline 2002 & Cúpula da UE, Barcelona & 300.000 \\
\hline 2002 & BM/FMI, Washington & 50.000 \\
\hline 2002 & G8, Calgary & $2.000-3.000$ \\
\hline 2002 & Antiguerra, Florence & 1.000 .000 \\
\hline 2003 & $\begin{array}{l}\text { Protestos Antiguerra, } 800 \\
\text { cidades }\end{array}$ & milhões \\
\hline 2003 & FSE, Paris & 100.000 \\
\hline 2003 & FSM, Porto Alegre & 75.000 \\
\hline 2003 & OMC, Cancun & $2.000-3.000$ \\
\hline 2003 & BM/FMI, Doha & $\begin{array}{r}\text { Protestos } \\
\text { proibidos por lei }\end{array}$ \\
\hline 2003 & G8, Evian & $\begin{array}{l}50.000- \\
100.000\end{array}$ \\
\hline 2004 & FSM, Bombaim & $\begin{array}{c}80.000- \\
90.000\left(115.000^{\mathrm{a}}\right)\end{array}$ \\
\hline 2004 & BM/FMI, Washington & $2.000-3.000$ \\
\hline 2004 & G8, Savannah & $1.000-2.000$ \\
\hline 2005 & FSM, Porto Alegre & 200.000 \\
\hline 2005 & Encontro OMC, Hong Kong & $10.000^{5.000-}$ \\
\hline
\end{tabular}




\begin{tabular}{|c|c|c|}
\hline 2005 & BM/FMI, Washington & 200 \\
\hline 2005 & G8, Edimburgo & 225.000 \\
\hline 2006 & $\begin{array}{l}\text { FSM Caracas } \\
\text { FSM Bamako } \\
\text { FSM Karachi }\end{array}$ & $\begin{array}{l}80.000 \\
11,000 \\
20,000\end{array}$ \\
\hline 2006 & BM/FMI, Singapura & $\begin{array}{r}\text { Protestos } \\
\text { proibidos por lei }\end{array}$ \\
\hline 2006 & G8, São Petersburgo & $150-300$ \\
\hline 2007 & FSM Nairóbi & $\begin{array}{l}66,000 \\
\left(57,000^{a}\right)\end{array}$ \\
\hline 2007 & BM/FMI, Washington & 300 \\
\hline 2007 & G8, Heiligendamm & $80.000^{25.000-}$ \\
\hline 2009 & FSM, Belém & $100.000^{a}$ \\
\hline 2011 & $\begin{array}{l}\text { FSM, primeiro em } 35 \text { lugares, } \\
\text { depois centralizado em Daka }\end{array}$ & $70.000^{\circ}$ \\
\hline
\end{tabular}

Fonte: Paczynska; salvo: *Smith; ${ }^{a}$ Rucht e Scerri ${ }^{27}$

Os protestos contracúpulas são o ponto de partida de uma nova fase de ativismo do MJG. Estes protestos massivos contra o encontro da OMC em Seattle em 1999 foram o mais relevante evento em termos de atenção da mídia e do impacto em encontros globais posteriores. ${ }^{28}$ Após Seattle, as cúpulas mundiais foram organizadas em lugares mais remotos. Em contraste com estes encontros cada vez mais exclusivistas que foram protegidos de quaisquer protestos de grande escala, o processo FSM foi iniciado como

\footnotetext{
${ }^{27}$ Paczynska, 2008 (aqui 9-12). Smith, 2008 (aqui 101). Rucht, 2011 (aqui 14). , ' Scerri, 2012.

${ }^{28}$ Giugni, Bandler and Eggert, 2006 (aqui 3). Smith, J. (2001) 'Globalizing Resistance. The Battle of Seattle and the Future of Social Movements', Mobilization, 6,1, 1-19.
} 
um modo alternativo e participativo de debate conjunto acerca de soluções. Objetivou criar alternativas às políticas formais, mudando valores da ordem sociopolítica dominante, ou quis oferecer lugares alternativos para a solução de problemas globais. ${ }^{29}$ O Jubileu 2000 foi uma grande campanha conduzida durante esses anos a fim de lutar pelo alívio das dívidas. ${ }^{30}$

Em 2001, o “Processo Fórum Mundial” começou em Porto Alegre. Em oposição ao Fórum Econômico Mundial, que acontece todo ano desde 1971 em Davos, ele enfatiza assuntos sociais, é hospedado em países do Sul do globo e pensado como um encontro de pessoas em vez de elites. O primeiro Fórum Social Mundial foi organizado por 8 organizações fundadoras e hospedado pelo Partido dos Trabalhadores (PT) em Porto Alegre. Houve em torno de 20.000 participantes de 100 países, entre os quais também 436 membros parlamentares. O número de participantes cresceu rapidamente para 150.000 no Fórum Social Mundial do ano seguinte, que foi organizado por mais ou menos os mesmos atores. ${ }^{31}$ Daí em diante, o Fórum Social Mundial foi organizado por equipes mais amplas e mais internacionais e deixou Porto Alegre, legando muitas tarefas organizacionais a comitês locais. Outro evento importante para o MJG foi o 11 de setembro de 2001. "Tanto os ativistas quanto os observadores concordam que a mudança fundamental na evolução do movimento por justiça global foram os ataques às Torres Gêmeas e ao Pentágono em 11 de setembro de 2001. [...] Embora manifestações de larga escala tenham diminuído nos Estados Unidos, o Movimento por Justiça Global, ao contrário de se desintegrar e desaparecer no esquecimento, desenvolveu uma variedade de outras táticas e estratégias para levar adiante sua agenda." 32 Paralelamente à guerra contra o terror, a paz se torna mais importante nos Fóruns Sociais após 2002. 33 Houve FSMs em Bombaim (2004), Caracas (Venezuela), Bamako (Mali) e Karachi (Paquistão) (todos em 2006), Nairóbi (Quênia) (2007), Belém (Brasil) (2008) e em Dakar (Senegal)

\footnotetext{
${ }^{29}$ Smith, 2008 (aqui 97).

${ }^{30}$ Smith, 2008 (aqui 100-101).

${ }^{31}$ Rucht, 2011 (aqui 13-14).

32 Paczynska, 2008 (aqui 1).

33 Pianta, Silva and Zola, 2004.
} 
(2011). ${ }^{34}$ Após o primeiro Fórum Social Mundial, fóruns nacionais se espalharam rapidamente sobretudo no Sul. ${ }^{35}$

A fase mais recente do movimento até agora é caracterizada por um foco no trabalho em nível local e na coordenação aprimorada via Internet, incluindo vários blogs e sites dedicados a informações alternativas, por exemplo as páginas da Indymedia, que foram amplamente usadas como um meio de informação independente da mídia dominante. A crescente comercialização, o estabelecimento e a burocratização dos Fóruns Sociais levam à criação de contrafóruns, que foram conduzidos paralelamente aos fóruns e serviram como um espaço para grupos mais radicais. ${ }^{36}$ Há um desacordo entre pesquisadores sobre como avaliar o estado atual do Movimento por Justiça Global. Por um lado, pesquisadores como Breno Bringel argumentam que o MJG morreu como um ator unitário, mas goza de boa saúde: ele apenas já não tem as mesmas características que tinha no início. As identidades se tornaram mais diversas, e não muitos ativistas hoje em dia se definem como parte do MJG. Suas ideias e práticas, contudo, continuam a ser relevantes, tais como a conexão global-local de ação coletiva transnacional e um mais amplo repertório de ação que foi desenvolvido pelo movimento ao longo das décadas passadas. ${ }^{37}$ A conexão global-local também ganhou nova importância: “os ativistas querem mudar o mundo começando localmente com as suas assembleias das vizinhanças." ${ }^{38}$ Pesquisadores como Dieter Rucht, por outro lado, não veem o MJG como morto. Ao contrário, ele menciona fatores que contribuíram para o fortalecimento do movimento: a crescente relevância de problemas transnacionais, o vasto potencial de movimentos no Sul global, a disponibilidade da Internet como uma ferramenta para a coordenação e a comunicação, e os processos passados de aprendizado com erros e experiências negativas. ${ }^{39} \mathrm{O}$ MJG perdeu um pouco da sua força durante os últimos cinco anos por várias razões. É difícil manter um movimento na alta intensidade que o MJG teve entre 1999 e $2006.4^{40}$ Cúpulas globais envolvem uma quantidade substancial de recursos

\footnotetext{
${ }^{34}$ Rucht, 2011 (aqui 14).

35 Pianta, Silva and Zola, 2004 (aqui 3).

${ }^{36}$ Bringel, B. and E. Muñoz, 2010 (aqui 32-34).

37 Bringel, B. and E. Muñoz, 2010 (aqui 35).

${ }^{38}$ Pleyers, 2010 (aqui 52).

${ }^{39}$ Rucht, 2011) (aqui 27).

${ }^{40}$ Bringel, B. and E. Muñoz, 2010 (aqui 34).
} 
pessoais e materiais e são, portanto, difíceis de manter por parte de atores que não são usualmente dotados de tais recursos. Contudo, as práticas cotidianas em nível local também não são sem limites. Elas precisam de menos recursos, mas "na maioria das vezes, elas quase não têm impacto no debate público." ${ }^{41}$ Especialmente nos Estados Unidos, os desdobramentos depois do 11 de Setembro imobilizaram os ativistas. ${ }^{42}$ Entretanto, contracúpulas e o processo Fórum Social continuam até hoje. O décimo Fórum Social Europeu aconteceu em Florença em novembro de 2012. O movimento está relacionado à nova onda de protestos e provavelmente readquire força em razão de novos protestos ao redor do mundo. Em fevereiro de 2013, decidiu-se situar o FSM de 2013 em Túnis, na Tunísia. ${ }^{43}$ Alguns autores chegam a ver o movimento Occupy como parte do MJG. ${ }^{44}$ Embora muitos ativistas do OWS tenham experiências no MJG, as novas ondas de protestos não são uma simples continuação do MJG. ${ }^{45}$

\section{A crítica da globalização do MJG}

Apesar da sua diversidade, o MJG tem objetivos e oponentes comuns. De acordo com Ulrich Brand, a globalização neoliberal é o contexto definitivo para o MJG: "uma estratégia competitiva para restabelecer o crescimento econômico e fortalecer o poder do capital em níveis local, nacional e internacional." ${ }^{46}$ Lauren Langman sublinha as cinco mais significativas disfunções da economia global que ensejaram o MJG: a atual redistribuição de riqueza de países pobres a países ricos; a erosão da autonomia da política de Estado; a universalização de uma cultura popular homogeneizada que serve cada vez mais a interesses econômicos; a destruição do meio ambiente; e as violações continuadas dos direitos humanos. ${ }^{47}$ Esses problemas, todos atribuídos ao sistema econômico global, são também uma razão para a natureza ampla do MJG, abrangendo vários grupos de questões particulares. O movimento mantém um modo específico de

\footnotetext{
${ }^{41}$ Pleyers, 2010 (aqui 87).

${ }^{42}$ Hayduk, 2012 (aqui 49).

${ }^{43}$ Scerri, 2012 (aqui 6).

${ }^{44}$ Brand, 2012 (aqui: 295).

${ }^{45}$ Hayduk, 2012) (aqui 43)

${ }^{46}$ Brand, 2012 (aqui 287).

47 Langman, L. (2005) 'From Virtual Public Spheres to Global Justice:. A Critical Theory of Internetworked Social Movements', Sociological Theory, 23, 1, 42-74.
} 
globalização responsável por problemas sociais, ambientais e políticos, entre outros. Este modo de integração econômica remonta a séculos, e igualmente as críticas que apontam os impactos sociais, econômicos e ambientais negativos, a resistência e as alternativas de desenvolvimento". ${ }^{48}$ Partes importantes deste modo de integração econômica são as instituições, como o Banco Mundial, o Fundo Monetário Internacional e a Organização Mundial do Comércio, todas criadas a partir do encontro de Bretton Woods em $1944 .{ }^{49}$ Mas essas instituições sozinhas não podem ser vistas como forças diretoras por trás do movimento. Ao contrário, a crise do sistema econômico e social que estas instituições não poderiam prever, antes intensificar, são vistas como uma razão de queixa ${ }^{50}$ relacionada ao movimento. "Ao longo das últimas décadas, políticas e reformas foram conduzidas pela agência neoliberal da eficiência, da competitividade e da orientação para o mercado mundial, da transformação do Estado, e da privatização de serviços públicos e programas de bem-estar social, tal como a seguridade social. [...] Assim, a relação de ganho essencialmente mediada pelo Estado é erodida e devolvida para o nível das empresas, resultando em uma perda massiva do poder dos assalariados e do trabalho organizado." ${ }^{51}$ A distância crescente entre os cidadãos e os centros de tomada de decisão política, não somente resultando da diminuição do poder do Estado nação, mas também das experiências negativas com os que tomam decisões politicas, é uma das forças diretoras da busca do MJG por uma democracia mais participativa. ${ }^{52}$ "Muitos críticos do capitalismo global apontam para o fato de que ele impede os cidadãos de participar das decisões mais cruciais que afetam as suas vidas." 53 As instituições das democracias representativas perderam legitimidade à medida que elas "se tornaram cada vez menos efetivas na representação e na resposta aos interesses populares sob o neoliberalismo". ${ }^{4}$ No nível da economia, de acordo com Duncan Green e seu colega,

\footnotetext{
${ }^{48}$ Broad, R. (ed.) (2002a) Global Backlash. Citizen Initiatives for a Just World Economy (Lanham: Rowman \& Littlefield).

${ }^{49}$ Smith, 2008 (aqui 55).

${ }^{50}$ Brand, 2012. McAdam, D. (1996) 'Conceptual origins, current problems, future directions' in D. McAdam, J. D. McCarthy, M. N. Zald (eds.) Comparative perspectives on social movements. Political Opportunities, Mobilizing Structures, and Cultural Framings (Cambridge: Cambridge Univ. Press) (aqui 25).

${ }^{51}$ Brand, 2012 (aqui 287)

52 Bringel, B. and E. Muñoz, 2010 (aqui 31).

53 Smith, 2008 (aqui 220).

${ }^{54}$ Smith, J. and N. Doerr (2011) 'Democratic Innovation in the U.S. and European Social Forums' in J. Smith,
} 
vários eventos fomentaram o desenvolvimento do MJG: "a crise do petróleo e a suspensão da conversibilidade do dólar em 1972 marcaram o fim de um ‘longo boom’ do keynesianismo pós-1945. Eles também causaram o aumento meteórico dos mercados de capital globais, que tornaram o ganho e a manutenção da 'confiança no mercado' um determinante cada vez mais importante das políticas governamentais". O quase colapso do México em razão da sua dívida externa em 1982 e o colapso do comunismo soviético (desde 1989) foram dois eventos importantes que marcaram o fim da era do pós-guerra de industrialização por substituição de importações. Vários países em desenvolvimento sofreram de um grande endividamento externo. A crise asiática de 1997 (causada em parte pela liberalização excessiva de mercados financeiros que foi então mal diagnosticada, agravada e perpetuada pelo FMI) foi talvez o evento mais significativo que minou a teoria neoliberal. Mas também a crise do peso mexicano de 1994 e a catástrofe da reforma do mercado livre na Rússia. A influência política do FMI, do Banco Mundial e dos mercados de capital internacionais aumentou, e a ideia de diminuir o Estado cresceu em importância. Houve um certo "consenso sobre o modelo de gerenciamento econômico e político global promovido por instituições globais e pelos atores estatais mais poderosos - um modelo variamente intitulado de 'neoliberalismo' ou de 'Consenso de Washington"”. ${ }^{55}$ Para colocar essas ideias em prática, houve várias tentativas de desregulamento e promoção do mercado livre, como o Acordo Geral sobre as Tarifas e o Mercado (GATT), que começou em 1986 por negociações acerca da agricultura, aspectos de direitos de propriedade intelectual relacionados ao comércio (TRIPS), medidas de investimento relacionadas ao comércio (TRIMs), e o Acordo Geral sobre Serviços de Comércio (GATS). Em 1995, a Organização para a Cooperação e o Desenvolvimento Econômico (OCDE) iniciou negociações sobre um acordo de investimento multilateral que estavam ligadas às negociações do GATT e ao Acordo Norte Americano de Livre Comércio (NAFTA). ${ }^{56}$

\footnotetext{
S. Byrd, E. Reese, E. Smythe (eds.) Handbook on World Social Forum Activism (Boulder, CO: Paradigm Publishers) (aqui 343).

${ }^{55}$ Green, D. and M. Griffith (2002) 'Globalization and Its Discontents', International Affairs,78, 1, 49-68 (aqui $51-52)$.

${ }^{56}$ Smythe, 2011 (aqui 169).
} 
Em termos de eventos, as grandes cúpulas internacionais e as grandes negociações que criaram a ampla zona NAFTA de mercado livre e o Acordo Multilateral sobre Investimento foram uma força condutora de grande importância por trás do MJG. "O movimento ganhou força à medida que as negociações secretas entre membros da Organização para a Cooperação e o Desenvolvimento Econômico (OCDE) acerca do Acordo Multilateral sobre Investimento se tornaram públicas no início de 1997."57 "Movimentos sociais e ONGs reconheceram a necessidade de criar e fortalecer redes globais para desafiar acordos de comércio e investimento internacional, que são os condutores principais de políticas globais neoliberais". ${ }^{8}$ Mas não foram somente as cúpulas econômicas internacionais que deram força ao MJG. Além disso, o fracasso das cúpulas da ONU e a frágil confiança nas ONGs para resolver o problema da crescente desigualdade mundial clamaram por abordagens alternativas. ${ }^{59}$ Com relação à infraestrutura organizacional e à cooperação internacional, é importante notar que o setor das ONGs cresceu muito. As ONGs foram "fundadas cada vez mais por organizações internacionais, tais como fundações privadas, as Nações Unidas e o Banco Mundial."60 O desenvolvimento de infraestrutura que inclui escritórios e recursos de viagem deu sustento ao aumento da cooperação de longo prazo em nível internacional. Desde meados dos anos 90, a cooperação ficou ainda mais fácil graças ao aumento da comunicação via internet.

\section{Os principais conflitos sociais, políticos, econômicos e culturais visados e}

\section{enquadrados pelo MJG}

Neste pano de fundo estrutural, os ativistas do MJG conceberam sua campanha com base em desenvolvimentos que redefiniram a função dos governos nacionais no sentido de reduzir funções distributivas do Estado de bem-estar e sua capacidade de controlar companhias multinacionais, assim como de marginalizar organizações internacionais voltadas para os direitos de bem-estar e os direitos humanos,

\footnotetext{
${ }^{57}$ Paczynska, 2008 (aqui 4).

${ }^{58}$ Smythe, 2011 (aqui 167).

${ }^{59}$ Bringel, B. and E. Muñoz, 2010 (aqui 31).

${ }^{60}$ Paczynska, 2008 (aqui 3-4).
} 
especialmente as ligadas às Nações Unidas. É também contra a ideologia da cultura de certo tipo de consumismo que favorece o grande negócio e deslegitima os oponentes do neoliberalismo. ${ }^{61} \mathrm{Em}$ face dos desenvolvimentos descritos acima, os "Movimentos sociais e as ONGs reconheceram a necessidade de criar e fortalecer redes globais para desafiar os acordos de investimento e comércio, os principais condutores de políticas neoliberais". ${ }^{62}$ Os campos de atividade do MJG são muito amplos. Os vários atores do movimento têm diferentes focos temáticos, mas as questões são muito mais livremente conectadas. Há um arcabouço de ideias muito coerente sobre razões de queixas e responsabilidades. "O desenvolvimento, questões econômicas e a democracia continuam a caracterizar o principal campo de atividades das organizações envolvidas na organização de eventos globais [...]. Sindicatos de trabalhadores e organizações de comércio, meio ambiente, direitos humanos e paz vêm na sequência." ${ }^{63}$ A liberalização do comercio tem sido uma das mais importantes questões do FSM desde 2001, mas talvez a mais importante em jogo é a natureza da democracia e da representação política. $O$ FSM desafia a "perda de legitimidade das instituições da democracia representativa, que se tornaram cada vez menos efetivas em representar e responder aos interesses populares sob o neoliberalismo". ${ }^{64}$ Neste ponto, está muito perto das demandas do atual movimento na Espanha, que também conecta várias questões sob a mesma reivindicação de democracia a partir de baixo. Além dos Fóruns Sociais que costumeiramente abarcam um amplo conjunto de questões, houve vários fóruns temáticos, e. g., sobre educação, saúde, democracia e direitos humanos. ${ }^{65}$

Os movimentos sociais "enquadram, ou atribuem significado para, e interpretam os eventos e as condições de maneira que possam mobilizar aderentes e constituintes potenciais, granjear o apoio de circunstantes, e desmobilizar antagonistas". ${ }^{66}$ Para fins de

\footnotetext{
${ }^{61}$ Smith, 2008 (aqui 69).

${ }^{62}$ Smythe, 2011 (aqui 167).

${ }^{63}$ Pianta, Silva and Zola, 2004 (aqui 3-4).

${ }^{64}$ Smythe, 2011 (aqui 167). Smith and Doerr, 2011 (aqui 343).

${ }^{65}$ Glasius, M. and J. Timms (2006) 'The Role of Social Forums in Global Civil Society. Radical Beacon or Strategic Infrastructure، in M. Glasius, M. Kaldor, H. Anheier (eds.) Global Civil Society 2005-2006 (London: Sage) (aqui 205).

66 Snow, D. and R. Benford (1988) 'Ideology, Frame Resonance, and Participant Mobilization' in B. Klandermans, H. Kriesi, S. Tarrow (eds.) From Structure to Action: Comparing Social Movement Research Across Cultures. International Social Movement Research. Volume 1 (London: JAI Press) (aqui 198).
} 
diagnóstico, o neoliberalismo é definido pelo MJG como a principal razão das várias queixas. O MJG argumenta que a "forma dominante de globalização econômica não é inevitável. Mas Guigni et al. (2006) argumentam que o neoliberalismo, para muitos dos grupos do MJG, não é bastante para mobilizar. Eles "sugerem estruturas de 'médio alcance' ou de nível intermediário que ligam a luta contra o neoliberalismo a questões e reivindicações mais específicas e que permitem a mobilização de muitos diferentes tipos de redes". ${ }^{67}$ Além disso, muitos dos grupos que protestam não são geralmente contra o capitalismo. Eles reivindicam a redução de "alguns dos perceptíveis efeitos maléficos de políticas e práticas por parte de instituições políticas e corporações globais". ${ }^{68} \mathrm{~A}$ globalização econômica é concebida como uma força que leva a uma "corrida para o nível mais baixo" com relação aos padrões de trabalho, à garantia de bem-estar ou às questões ecológicas, apenas para mencionar algumas preocupações. Além disso, a economia global é acusada de minar as instituições democráticas. ${ }^{69}$ A rejeição do neoliberalismo global, contudo, não significa a rejeição da globalização. Segundo Mario Pianta e seus colegas, a maior parte dos atores do MJG são a favor de formas alternativas de "globalização a partir de baixo" ou "globalização humanizada", colocando a sociedade civil e os seres humanos no centro. Apenas $4 \%$ se autodenominam de "antiglobalização". 70

Encontrar soluções para os problemas causados pelo neoliberalismo é mais complicado. Grande parte do movimento é a favor da "transformação em vez da revolução". ${ }^{71}$ Uma solução parcial praticada é defender os direitos estabelecidos. Isto, contudo, não é suficiente. "Paralelamente à luta contra o neoliberalismo, o MJG clama por maior participação dos cidadãos nos processos e nos espaços de tomada de decisões, ambos nos níveis local e global. ${ }^{72} \mathrm{O}$ movimento reivindica "formas de governança global centradas mais nas pessoas do que nos mercados" e desglobalização. ${ }^{73}$ Este conceito de desglobalização envolve: "redução da dependência em investimentos estrangeiros,

\footnotetext{
${ }^{67}$ Giugni, Bandler and Eggert, 2006 (aqui 15).

68 Ibrahim, 2009 (aqui 398).

${ }^{69}$ Smith, 2008 (aqui 6).

${ }^{70}$ Pianta, Silva and Zola, 2004 (aqui 6).

${ }^{71}$ Pleyers, 2010 (aqui 91).

72 Giugni, Bandler and Eggert, 2006 (aqui 6).

73 Smith, 2008 (aqui 4).
} 
redistribuição de renda e terra, retirada da ênfase no crescimento e na maximização, abandono da governança pelo mercado, monitoramento constante do Estado e do mercado pela sociedade civil, reorientação da produção para longe de bens remotos". ${ }^{74} \mathrm{~A}$ maior parte das atividades a favor da ideia de "encolher ou afundar as instituições financeiras globais para eliminar vantagens injustas de países ricos e cooperações [...] fortalecem a governança econômica em nível global através, por exemplo, da taxa Tobin, [...] do alívio da dívida para países pobres, [...] do fortalecimento da soberania estatal, [...] da ênfase no empoderamento econômico local e [...] da promoção de direitos humanos". ${ }^{75}$ As queixas e a resistência locais estão sempre conectadas às políticas de neoliberalismo econômico e a processos globais. ${ }^{76}$

Comparando o MJG com outros movimentos, vemos que os valores e as questões do MJG não diferem fundamentalmente dos da onde de contenção que o precedeu, nomeadamente os dos novos movimentos sociais. ${ }^{77}$ Todos eles reivindicam, por exemplo, igualdade, democracia a partir de baixo, ou uma maneira alternativa de viver ecologicamente estável. Com relação à reivindicação de democracia mais participativa, os movimentos dos Indignados ${ }^{78}$ e do Occupy empregam novas formas de tomada de decisão e técnicas de democracia deliberativa. ${ }^{79}$

\section{Formas de Protesto}

O enquadramento das questões em jogo por parte dos ativistas do MJG também tem implicações para as formas de protesto que tem adotado. O MJG é caracterizado por duas grandes formas de eventos de protesto: "manifestações de massa e atividades de protesto dirigidas contra as principais instituições governamentais ou organizações privadas ou internacionais, por um lado, e fóruns sociais por outro". 80 Duas dessas mais visíveis formas dos MJGs foram organizadas principalmente na forma de grandes

\footnotetext{
${ }^{74}$ Smith, 2008 (aqui 205).

75 Smith, 2008 (aqui 6).

${ }^{76}$ Paczynska, 2008 (aqui 4).

77 Giugni, Bandler and Eggert, 2006 (aqui 15).

${ }^{78}$ Romanos, 2013.

${ }^{79}$ Hayduk, 2012 (aqui 44).

${ }^{80}$ Giugni, Bandler and Eggert, 2006 (aqui 7).
} 
contracúpulas, pelo menos relacionadas temporalmente a cúpulas globais, mas frequentemente organizadas perto dos locais das cúpulas. ${ }^{81}$

O estudo de Pianta sobre os eventos da sociedade civil global incluiu a parcela de tais eventos de 2003 e 2004: $30 \%$ de todos os eventos foram fóruns sociais, $26 \%$ foram cúpulas paralelas com conferências regionais (União Europeia, encontros governamentais americanos ou asiáticos), 21\% foram encontros organizados independentemente de cúpulas oficiais, $9 \%$ foram eventos paralelos às conferências da União Europeia, e 7\% foram contraprotestos contra o FMI, o Banco Mundial ou os encontros da OMC e contra as cúpulas do $G 8 .^{82}$ Cerca de $50 \%$ dos eventos de protesto acontecem ao redor de tais encontros. Levando em consideração a novidade e o impacto desses encontros, Rucht argumentou que "o processo Fórum Social Mundial (FSM) é a mais importante manifestação dos movimentos por justiça global contemporâneos (MJGs)". ${ }^{83}$ Em relação às mais comuns formas de ativismo, dados de pesquisa mostram que manifestações e petições são muito comuns, "enquanto táticas de confronto, tais como bloqueios e ocupação, têm sido aplicadas por mais ou menos um quarto deles [...] As organizações dos MJGs não se enquadram nos grupos que usam formas moderadas de ação ou outros grupos que usam meios radicais. Em vez disso, formas de ação de confronto são um apêndice ao repertório moderado. ${ }^{84}$

Enquanto grandes e visíveis eventos contribuíram para a fama do MJG, estes eventos são apenas uma parte do movimento. Rucht descreve o FSM como "não um evento, mas uma rede de comunicação global que permanece, apenas em parte, numa infraestrutura visível". ${ }^{85}$ De modo semelhante, Jackie Smith afirma: "A noção do FSM como um 'processo' assinala a ideia de que os encontros mesmos não são o principal propósito. Ao contrário, o objetivo da maior parte dos organizadores é facilitar a troca de ideias, expandir e aprofundar redes de ativistas, e fornecer novos espaços nos quais as

\footnotetext{
${ }^{81}$ Rucht, 2011 (aqui 12).

${ }^{82}$ Pianta, Silva and Zola, 2004 (aqui 3).

${ }^{83}$ Rucht, 2011) (aqui 11).

${ }^{84}$ Rucht, D. and S. Teune (2009) 'Forms of Action of Global Justice Movement Groups. Do Conceptions and Practices of Democracy Matter?‘ in D. Della Porta (ed.) Democracy in Social Movements (Basingstoke: Palgrave Macmillan) (aqui 177-178).

${ }^{85}$ Rucht, 2011 (aqui 16).
} 
pessoas possam refletir sobre e ajudar a realizar alternativas à globalização neoliberal."86 Os Fóruns Sociais são abertos para todos os que se opõem ao neoliberalismo global, salvo os extremistas de extrema direita e grupos que usam de violência. Ademais, partidos políticos e funcionários governamentais eleitos, na sua função oficial, estão em princípio excluídos, o que é uma prática não observada consistentemente. A ideia dos fóruns é dar voz para todos os participantes. Devido à sua prominência, contudo, tem havido muitos palestrantes importantes que, naturalmente, atraem uma audiência maior. Este culto a estrelas é criticado e os Fóruns Sociais Mundiais de 2005 e 2007 evitaram promover palestrantes proeminentes. ${ }^{87} \mathrm{O}$ formato básico do fórum assemelhou-se, de vários modos, às conferências da sociedade civil que aconteceram em paralelo às conferências globais da ONU na década de 1990. Também espelha o modelo forjado pelas ativistas feministas na América Latina, que se reuniram no que foi chamado de encuentros". ${ }^{88}$ Os Fóruns Sociais também têm muito em comum com as atuais assembleias do $15 \mathrm{M}$ na Espanha. As assembleias, assim como os Fóruns Sociais, são abertos a diferentes ideias, que são consideradas enriquecedoras. A estrutura organizacional dos movimentos não é hierárquica, mas feita de assembleias abertas, grupos de trabalho e redes de cooperação com uma constante mudança de posições e sem porta-vozes. Os níveis local e global estão conectados estruturalmente e há uma pragmática entre diferentes tipos de organizações que leva em consideração as diferentes possibilidades de cada ator. ${ }^{89}$

Há uma divisão entre deliberação e luta: alguns atores do MJG colocam a deliberação em primeiro lugar. ${ }^{90}$ Eles costumam favorecer um FSM que seja tão aberto quanto possível a novas ideias, valores e debates em si mesmos. Para os grupos que favorecem a luta, debates abertos não são suficientes, eles objetivam construir um contrapoder. As posições são dois extremos num contínuo. "Os mais vibrantes debates

\footnotetext{
${ }^{86}$ Smith, J. G., S. Byrd, E. Reese and E. Smythe (2011) 'Introduction' in J. Smith, S. Byrd, E. Reese, E. Smythe (eds.) Handbook on World Social Forum Activism (Boulder, CO: Paradigm Publishers).

Smith, J., S. Byrd, E. Reese and E. Smythe (eds.) (2011b) Handbook on World Social Forum Activism (Boulder, CO: Paradigm Publishers) (aqui 2).

${ }^{87}$ Rucht, 2011 (aqui 18-19).

${ }^{88}$ Smith, 2008 (aqui 208).

${ }^{89}$ Nistal, T. A. (2012) 'Antecedents, Achievements and Challenges of the Spanish 15M Movement' in B. Tejerina, I. Perrugorra (eds.) From Social to Political. New Forms of Mobilization and Democratization (Bilbao: Bizkaia Aretoa) 74-88 (aqui 84).

${ }^{90}$ Glasius and Timms, 2006 (aqui 223).
} 
se deram sobre a incapacidade do FSM, ou a sua falta de vontade, de tomar posições estratégicas. Ver o fórum como um lugar de debate em vez de um ator unificado evita construir posições comuns e declarações. Assim, enquanto uma estrutura aberta costuma ser louvada, houve uma crescente insatisfação com o fracasso dos movimentos em gerar decisões ou ações políticas.

\section{Principais Atores e Movimentos do MJG}

A diversidade dos principais atores e movimentos que compõem o MJG reflete a diversidade dos movimentos em termos de seus objetivos e formas de protesto. ${ }^{91}$

O MJG compreende uma ampla variedade de ativistas e seus grupos e organizações. Eles não somente se encontram nos Fóruns Sociais e contracúpulas, mas também lançam campanhas políticas independentes. ${ }^{92}$ Marco Guigni et al. "distinguem entre dois tipos básicos de estruturas de mobilização: (i) organizações formais - por exemplo, a Associação pela Tributação das Transações Financeiras para Ajuda aos Cidadãos (ATTAC); e (ii) redes informais - ou seja, a rede de contatos e trocas interpessoais entre ativistas e participantes de movimentos". ${ }^{93}$ Jackie Smith distingue ainda várias correntes de organizações: ativismo contra o livre comércio, trabalho transnacional, ambientalismo transnacional, direito das mulheres, a taxa Tobin, a paz. ${ }^{94}$

Já há pesquisa substancial sobre os atores que estão envolvidos na organização de Fóruns Sociais. "O primeiro FSM foi organizado por um grupo de sete representantes dos grupos que lançaram os eventos. De 2002 em diante, o FSM é organizado pelo Conselho Internacional, que se reúne algumas vezes, mas que coordena o FSM principalmente via Internet. Comitês locais lidam com questões logísticas e técnicas e estabelecem o programa. O Conselho Internacional inclui várias centenas de grupos e redes (por exemplo, 100 em 2003 e 156 em 2010)". 95 “Em alguns casos, normalmente, nos Fóruns Sociais Mundiais, há mais de 400 organizações envolvidas [na organização de eventos].

\footnotetext{
${ }^{91}$ Rucht, 2011 (aqui 20-21).

${ }^{92}$ Brand, 2012 (aqui 290).

93 Giugni, Bandler and Eggert, 2006 (aqui 8).

${ }^{94}$ Smith, 2008 (aqui 102-103).

${ }^{95}$ Rucht, 2011 (aqui 19).
} 
Geralmente, contudo, o número de organizações que trabalham juntas tem um tamanho mais gerenciável, abaixo de 24 num quarto dos casos, entre 25 e 49 em 30\% dos casos, e entre 50 e 199 em $23 \%$ dos casos". ${ }^{96}$

Dentro do MJG, há muitos diferentes tipos de atores, como por exemplo organizações não-governamentais, grupos anarquistas, grupos ambientalistas, redes de atores, como a AMP, autônomos, movimentos indígenas, grupos socialistas, grupos contra corporações e contra guerras. ${ }^{97}$ Esses atores variam não somente em termos de sua orientação política, formas de ação preferidas, ou acesso a fontes e alianças; eles também podem ser distinguidos pela natureza das suas estruturas organizacionais. Podemos distinguir dois tipos principais de estrutura organizacional, a horizontal e a vertical. ${ }^{98}$ Grupos com uma estrutural mais vertical (tais como sindicatos do comércio) costumam praticar eleições e têm hierarquias, enquanto grupos mais horizontais são contra tais estruturas e práticas organizacionais hierárquicas. "As organizações da velha esquerda foram fundadas na maior parte antes de 1968 e tendem a ter mais de 100.000 membros. A maior parte dos grupos da nova esquerda, anarquistas e autônomos foram fundados entre 1969 e 1989 e têm em geral entre 100 a 1.000 membros. A maioria dos novos grupos de movimentos sociais foi fundada no mesmo período, mas tem um maior número de membros (de 1.000 a 10.000 membros). Organizações de solidariedade, paz ou direitos humanos foram fundadas sobretudo entre 1990 e 1999 (um número considerável, contudo, também antes de 1968 ou entre 1969 e 1989) e tendem a ter entre 1.000 e 10.000 membros. Finalmente, novos grupos que agem principalmente em nível global foram fundados nos anos 2000 e depois, e são na maioria pequenos (com até 100 membros)". ${ }^{99}$ Um exame mais atento da estrutura dos participantes dos Fóruns Sociais mostra a importância de grupos e organizações de ativistas: "a maior parte dos participantes são membros ou delegados formais de grupos políticos ou sociais, tais como associações indígenas, movimentos de fazendeiros, sindicatos do comércio e ONGs. Ademais, ativistas independentes, intelectuais, artistas e jovens não afiliados

\footnotetext{
${ }^{96}$ Pianta, Silva and Zola, 2004 (aqui 3).

97 Ibrahim, 2009 (aqui 397).

${ }^{98}$ Rucht, 2011 (aqui 22). Glasius and Timms, 2006 (aqui 222).

99 Reiter, H. (2009) 'Participatory Traditions within the Global Justice Movement' in D. Della Porta (ed.) Democracy in Social Movements (Basingstoke: Palgrave Macmillan) (aqui 50-51).
} 
participam". ${ }^{100}$ Entre os participantes do Fórum Social Europeu de Florença (2002), 34,6\% pertenciam a algum partido político, 36,6\% eram ligados a sindicatos, 52,7\% a movimentos sociais, e $41,5 \%$ a ONGs. ${ }^{101}$

Fora os grandes fóruns visíveis e os eventos de protesto, há vários grupos importantes, embora menos visíveis, que trabalham em nível local em todo o mundo. Geoffrey Pleyers resume este princípio organizacional fundamental do MJG como segue: “Os ativistas querem mudar o mundo começando localmente com suas assembleias nas suas vizinhanças." 102 Soluções alternativas são praticadas nesses grupos e nesses projetos de pequena escala. Este princípio é repetido dentro das assembleias atuais, como o 15M espanhol, que, após a ocupação central de Puerta del Sol, se espraiou para os "Bairros". ${ }^{103}$ Examinando a estrutura organizacional dos movimentos, encontramos muitas continuidades, por exemplo, uma "superposição entre o Conselho Internacional do FSM e a rede Nosso Mundo, que pela primeira vez protestou contra a OMC". ${ }^{104}$ De acordo com Hayduk, muitos ativistas do Occupy Wall Street vêm "diretamente do movimento antiglobalização." ${ }^{105}$ O 15M na Espanha está conectado aos movimentos anárquicos espanhóis. Minhas próprias observações em Portugal, por outro lado, mostram muito pouca conexão dos atuais movimentos antiausteridade com o MJG, especialmente com os processos Fórum Social. Embora a cooperação transnacional fosse considerada importante, quase nenhum os movimentos, durante o seu primeiro ano de existência, teve laços transnacionais institucionalizados. A troca de ideias era feita principalmente por meio de contatos pessoais, estudantes do Erasmus e com grupos bem conhecidos via Internet. No meu estudo sobre Portugal, não encontrei o uso de antigos contatos dos MJGs. ${ }^{106} \mathrm{O}$ recente movimento espanhol 15M também envolveu um grande número de pessoas sem experiência em grupos e organizações da sociedade civil. Além

\footnotetext{
${ }^{100}$ Rucht, 2011 (aqui 14-15).

${ }^{101}$ Della Porta, D. (2005) The Social Bases of the Global Justive Movement. Some Theoretical reflections and Empirical Evidence from the First European Social Forum (New York: UNRISD/UN Publications) (aqui 11).

${ }^{102}$ Pleyers, 2010 (aqui 41).

${ }^{103}$ Nistal, 2012 (aqui 76).

${ }^{104}$ Smythe, 2011 (aqui 172).

${ }^{105}$ Hayduk, 2012 (aqui 43).

${ }^{106}$ Baumgarten, 2013.
} 
disso, muitos dos grupos envolvidos na organização são novos. ${ }^{107}$ Destarte, embora alguns grupos e ativistas tenham estado envolvidos em velhas lutas, em termos de atores os recentes movimentos não são simples continuidades do MJG.

\section{Principais áreas geográficas do MJG}

O MJG é um movimento muito globalizado com atores e eventos localizados em todo o mundo. É baseado em redes transnacionais de atores locais, nacionais e transnacionais. Há, contudo, alguns espaços especialmente importantes que deram forma ao movimento. As contracúpulas sempre aconteceram perto das cúpulas do Banco Mundial, da OMC ou do FMI. Apesar de todas as dificuldades ligadas a lugares como Davos ou Doha, incluindo-se banimento de protestos, grande presença policial ou dificuldade para atingir lugares remotos, os ativistas protestaram tão perto quanto possível dos lugares das respectivas cúpulas. Em termos dos Fóruns Sociais, Porto Alegre, no Sul do Brasil, tem um papel importante. O processo FSM começou aí e foi moldado especialmente por atores brasileiros e franceses. Em contraste com protestos contracúpula, o local foi escolhido por causa da sua infraestrutura favorável. Embora o movimento seja global, as redes de atores envolvidos nos movimentos estão inseridas em contextos nacionais. Seu trabalho diário acontece em arenas locais, frequentemente tendo com alvo políticas locais e nacionais. Os participantes em eventos de protestos globais e Fóruns Sociais vêm predominantemente do país em que o evento ocorre. A distribuição geográfica dos participantes do FSM de Porto Alegre em 2005 ilustra bem isso: $80 \%$ dos participantes vieram do Brasil, $8,8 \%$ de outros países latino-americanos e $4,5 \%$ da Europa. ${ }^{108}$ O protesto contracúpula de Seattle em 1999 foi dominado por ativistas americanos, e o maior contingente de participantes em qualquer FSM é do respectivo país anfitrião. ${ }^{109}$ "Associações nacionais e ONGs são sempre atores principais na

\footnotetext{
107 Romanos, 2013. Fuster Morell, M. (2012) 'The Free Culture and 15M Movements in Spain: Composition, Social Networks and Synergies‘, Social Movement Studies, DOI:10.1080/14742837.2012.710323, 1-7 (aqui 3). Baumgarten, 2013.

108 Smith, P. J. and E. Smythe (2011) '(In)Fertile Ground? social Forum Activism in its Regional and Local Dimensions' in J. Smith, S. Byrd, E. Reese, E. Smythe (eds.) Handbook on World Social Forum Activism (Boulder, CO: Paradigm Publishers9 (aqui 31).

${ }^{109}$ Giugni, Bandler and Eggert, 2006 (aqui 13).
} 
organização de eventos da sociedade civil global, juntando-se, em muitos casos, com ONGs e redes internacionais. Contudo, grupos locais continuam a ter um papel-chave na maior parte dos eventos". ${ }^{110}$ Se os atores locais e nacionais desempenham um maior papel nos eventos, então vale a pena observar a distribuição dos eventos para mapear as principais áreas geográficas do movimento também para um movimento global. Baseado em uma análise de 43 eventos da sociedade civil em 2003 e nos primeiros seis meses de 2004, Pianta e colegas contam um terço dos eventos na América Latina, um quarto na Europa, um quinto na Ásia e Oceania, 12\% na América do Norte e 7\% na África. Num estudo mais amplo focado em eventos do Fórum Social, Smith conta 600 eventos entre 2001 e 2006. ${ }^{111}$ Mais da metade deles (306) aconteceu na Europa, 70 na América do Sul, 38 na África, 28 na América do Norte e 5 na Oceania. A distribuição das organizações envolvidas na organização dos eventos neste período de tempo é também desigualmente distribuída: 354 vêm da Europa, 125 da América do Sul, 62 da África, 39 da América do Norte, e 15 da Oceania. Estas diferenças são causadas principalmente pelos Fóruns Sociais locais e nacionais naquele período de tempo em que aconteceram predominantemente na Europa. O Fórum Social Europeu é o maior Fórum Social após o FSM. ${ }^{112}$ Ademais, entre 2001 e 2004 houve 283 Fóruns Sociais locais na Itália e mais ou menos o mesmo número na Grécia. ${ }^{113}$ Esses dois países foram portanto os lugares mais importantes para o ativismo de fóruns sociais locais. Considerando tais eventos, o movimento tem ênfase na América Latina e na Europa.

Durante o seu tempo de existência, o movimento se tornou mais descentralizado. ${ }^{14} \mathrm{~A}$ estrutura organizacional do FSM mudou especialmente entre $2003 \mathrm{e}$ 2005. Não só aumentou de tamanho, mas também desenvolveu um aspecto mais horizontal. Com inovações técnicas da Internet, alguns dos processos preparatórios foram mudados para esta arena. ${ }^{115}$

\footnotetext{
${ }^{110}$ Pianta, Silva and Zola, 2004 (aqui 3).

${ }^{111}$ Smith, J. G. (2011) 'Creating Spaces for Global Democracy: The World Social Forum Process in L. Reydams (ed.) Global activism reader (New York: Continuum) (aqui 33).

${ }^{112}$ Glasius and Timms, 2006 (aqui 205).

${ }^{113}$ Smith, 2008 (aqui 212).

${ }^{114}$ Bringel, B. and E. Muñoz, 2010 (aqui 34).

${ }^{115}$ Byrd, S. C. and L. Jasny, 'Transnational Movement Innovation and Collaboration. Analysis of World Social Forum Networks', in J. Smith, S. Byrd, E. Reese, E. Smythe (eds.), Handbook on World Social Forum Activism
} 
A partir de 2005, podemos observar um processo de desregionalização para fora do Brasil. Este processo foi acompanhado pela emergência de uma estrutura autoorganizativa, um processo mais aberto de consulta no que diz respeito aos temas que os protestos deveriam abordar. Esses processos levaram a mais cooperação e enredamento antes do Fórum. Ao se descentralizar, o movimento está seguindo a ideia dos Zapatistas de "resistir onde quer que você esteja". ${ }^{116}$ A descentralização foi também iniciada pelos organizadores dos fóruns que objetivavam uma mais ampla participação, especialmente daquelas pessoas que não têm condições de viajar longas distâncias. ${ }^{117}$ Para tornar mais fácil a participação dessas pessoas que não estão acostumadas com eventos internacionais, a questão da língua se tornou importante. Já no FSM de 2005 houve 16 línguas oficiais e 533 intérpretes oficiais. ${ }^{118}$

A tensão entre "o global" e "o local", como Tejerina argumenta, não é apenas uma tensão interior ao MJG, mas também aos movimentos atuais, embora estes não estejam ainda tão globalizados. ${ }^{119}$ Segundo Tajerina: “o movimento alter-global optou por buscar ações 'glocais'. Como consequência, esteve em oscilação permanente entre o fixo (aqui e agora) e o móvel (lá e antes-depois). Esta opção definiu o movimento alter-global e the conferiu uma especificidade quando comparado a prévios processos de mobilização. Muitos militantes do $15 \mathrm{M}$, particularmente os mais jovens, mostraram uma 'vocação internacional' ou global; eles estão conscientes da importância de conseguir apoio em outros países". ${ }^{120}$

\section{Impactos e resultados}

Os resultados dos movimentos sociais são difíceis de medir. Eles não somente incluem o impacto político, mas também, por exemplo, mudanças culturais de longo prazo e desenvolvimentos internos dos movimentos. Em geral, os resultados se

\footnotetext{
(Boulder, CO: Paradigm Publishers, 2011), 355-372 (aqui 362-363).

${ }^{116}$ Pleyers, 2010 (aqui 93).

117 Smith, 2008 (aqui 212).

${ }^{118}$ Glasius and Timms, 2006 (aqui 199). About the issue of language in the WSFs and ESFs see: Doerr, N. (2008) 'Deliberative Discussion, Language, and Efficiency in the World Social Forum Porcess ', Mobilization, $13,4,395-410$.

${ }^{119}$ Baumgarten, 2013.

${ }^{120}$ Tejerina, Perrugorra, 2012 (aqui 100).
} 
desenvolvem em processos complexos e, assim, frequentemente não podem ser atribuídos a um único movimento ou campanha. Em comparação com outros movimentos desta magnitude, o MJG ainda é muito jovem. Contudo, seu impacto e seus resultados já estão em evidência. A primeira fase do MJG contribuiu em particular para o fortalecimento de instituições multilaterais e para a democratização de políticas globais. ${ }^{121}$ O sucesso extraordinário do FSM reside no fato de que ele emergiu de uma história extensa de ativismo transnacional que havia construído a fundação de redes capazes de disseminar as ideias sobre a iniciativa e de fornecer recursos e motivação aos participantes". ${ }^{122}$

No nível discursivo há um importante impacto de várias campanhas do movimento visível: "números cada vez maiores de funcionários públicos estão fazendo eco às reivindicações dos atores de movimentos sociais para demandar esforços para fortalecer a democracia". Nos últimos anos, o sistema atual tem sido criticado por importantes porta-vozes "que foram uma vez (e podem ainda ser) simpáticos à agenda neoliberal”. ${ }^{123}$

O MJG não foi somente bem sucedido em mudar discursos, mas também deixou suas marcas na política. “Os MJGs são, e têm sido, capazes de politizar certos aspectos da globalização capitalista, mas foram incapazes de intervir naquelas relações de poder. 0 poder do capital e seus aliados no sistema político, na ciência e na mídia ainda parece forte demais para que nasçam alternativas sociais mais amplas". ${ }^{124}$ Contudo, os protestos tiveram um impacto político tangível: "Os políticos reconheceram a necessidade de responder à inquietação do público, por exemplo na decisão dos $G 8$ de colocar a dívida na agenda, em sua cúpula de Birmingham de 1998, ou quando o Chanceler Schroeder e o Primeiro Ministro Jospin pediram um estudo sobre a taxa Tobin em 2001. Em 1999, o FMI se comprometeu com os objetivos de diminuir até 2015 a pobreza mundial pela metade, traçados pelo OECD e que tiveram a concordância na Cúpula do Milênio da ONU, realizada em Genebra em junho de 2000". ${ }^{125}$

\footnotetext{
${ }^{121}$ Smith, 2008 (aqui 14).

${ }^{122}$ Smith, 2008 (aqui 207).

${ }^{123}$ Smith, 2008 (aqui 11 e 58).

${ }^{124}$ Brand, 2012 (aqui 295-296).

${ }^{125}$ Green, D. and M. Griffith (2002) 'Globalization and Its Discontents',International Affairs,78, 1, 49-68 (aqui 60-61).
} 
O alívio da dívida como uma questão política foi apresentada ao mundo principalmente pela campanha do Jubileu de 2000. A ideia do alívio da dívida tornou-se importante, bem como as práticas de códigos de conduta, por exemplo, promovidas nos movimentos das Clean Clothes Campaigns. Práticas de negócios estão mais sob estrita observação por parte do público e dos consumidores, e a exploração e as desigualdades tornaram-se mais visíveis - também por causa das várias campanhas promovidas pelo MJG. ${ }^{126}$ A campanha contra o Acordo Multilateral sobre Investimentos foi bem sucedida, pois o acordo foi rejeitado. Além disso, a ideia de responsabilidade social corporativa ${ }^{127}$ ganhou importância nos últimos anos. Esses sucessos parciais têm fortalecido os reformistas dentro do movimento.

Em um nível fundamental, o MJG também contribuiu para a democratização da sociedade: não somente por suas exigências, mas sobretudo por suas próprias práticas de organização e de encontros. ${ }^{128}$ Especialmente, os Fóruns Sociais ajudaram a disseminar o modelo das assembleias de orçamento participativo, que já era praticado em Porto Alegre antes do Fórum Social Mundial. Em termos de resultados internos, o movimento tem desenvolvido práticas de tomada de decisão e participação. As ligações entre os vários tipos de grupos de ativistas de todo o mundo foram reforçadas. O MJG desenvolveu uma infraestrutura como um "nó de informação, comunicação e organização de diferentes tipos de movimentos que atuam em diferentes níveis". ${ }^{129}$ Continua a ser uma questão para futuras pesquisas, contudo, até que ponto esta infraestrutura serve aos movimentos atuais. A falta de contatos internacionais na primeira fase dos movimentos atuais em alguns países sugere antes que estes não poderiam ser facilmente contemplados. Entre os atores do MJG, contudo, há muitos contatos de longo prazo e muitas vezes institucionalizados, que, por exemplo, resultaram em campanhas conjuntas, ONGs e associações internacionais.

\footnotetext{
${ }^{126}$ Paczynska, 2008 (aqui 15).

${ }^{127}$ Green, D. and M. Griffith (2002) 'Globalization and Its Discontents',International Affairs,78, 1, 49-68 (aqui 54-55).

${ }^{128}$ Giugni, Bandler and Eggert, 2006 (aqui 6).

${ }^{129}$ Rucht, 2011 (aqui 24).
} 


\section{Conclusão}

Este capítulo mostrou que o MJG é extremamente difícil de conceituar. Em razão da sua grande diversidade, muitas fronteiras que definem um movimento social são indistintas. A sua coerência interna tampouco pode ser facilmente descoberta. 0 movimento inclui atores que não são geralmente parte de movimentos sociais, tais como políticos de partido e atores estatais nos Fóruns Sociais. Ademais, como o movimento é feito de uma conjunção dos movimentos anteriores, é uma questão de definição identificar o começo do movimento. Enquanto os contraprotestos pertencem ao repertório clássico dos movimentos sociais, Fóruns Sociais são descritos como “ajuntamento autônomo". ${ }^{130}$ Esta questão dá origem à pergunta se um Fórum Social ainda pode ser significativamente analisado sob a rubrica de "movimentos sociais". Eu considero os Fóruns Sociais como eventos organizados por um movimento social. Não há, no entanto, consenso na literatura quanto à possibilidade de considerar o FSM como um espaço ou como um ator. ${ }^{131}$ Na prática, este problema está ligado à questão de saber se o Fórum Social deve expressar uma posição sobre questões políticas, ou se deve ser apenas um local de encontro onde diversas opiniões são debatidas.

Apesar de sua grande diversidade de atores e objetivos, este capítulo mostrou como o MJG pode ser conceituado como um movimento. Entre os seus atores há um sentimento de pertencer a este movimento global. Eventos conjuntos e campanhas são importantes para manter viva a cooperação entre os atores, mas o movimento também desenvolveu uma infraestrutura de cooperação que inclui não somente contatos informais, mas também cooperação de longo prazo e redes globais dos atores do MJG.

Algumas das principais características do MJG também podem ser encontradas nos novos movimentos Indignados e Occupy. Eles têm em comum o caráter espetacular de formas de ação, a comunicação via Internet e as reivindicações radicais contra o sistema. Os novos movimentos, no entanto, não compartilham a orientação do MJG para os contraeventos. Eles também são muito menos globalizados em sua estrutura organizacional e em suas reivindicações. O MJG desenvolveu uma rede global ao longo do

\footnotetext{
${ }^{130}$ Smith, 2011 (aqui 348).

${ }^{131}$ Smith, 2011 (aqui 348).
} 
tempo, incluindo uma alta frequência de contatos, encontros e eventos conjuntos. Os ativistas dos movimentos atuais não usam esta rede. Eles se mantêm informados sobre o que acontece em outros países e planejam dias de ação global através da Internet, mas não têm a estrutura de reuniões globais regulares e atividades conjuntas do MJG. Embora os novos movimentos de contestação se refiram uns aos outros, cada movimento está também muito mais inserido no seu contexto nacional.

Em termos de questões e sua estruturação, o MJG está intimamente relacionado com os Indignados e o movimento Occupy. O MJG e estes movimentos, no entanto, não estão ligados por uma identidade comum, não sendo os principais agentes, na maior parte, os mesmos. Esses novos movimentos ganharam, em certa medida, com as experiências do MJG. As práticas de deliberação, as reuniões abertas, as ideias de unidade na diversidade e de "andar devagar, porque há um longo caminho para percorrer" foram tomadas do MJG. Alguns grupos do MJG desempenharam um papel importante, especialmente no movimento Occupy dos EUA e na Espanha. Os movimentos atuais, no entanto, não aproveitaram tanto os contatos transnacionais estabelecidos. A cooperação em nível transnacional ainda está em seu início e restrita principalmente a dias de ação conjunta, trocando informações pelo Facebook e em listas de discussão, contatos pessoais e em alguns casos convidando palestrantes de fora. ${ }^{132} \mathrm{~A}$ análise detalhada do impacto do MJG nestes movimentos contemporâneos, suas semelhanças e diferenças, continua a ser uma questão para pesquisas futuras.

\section{Referências Bibliográficas}

BAUMGARTEN, B. Geração à Rasca and Beyond. Mobilizations in Portugal after 12 March 2011. Current Sociology, v. 61, n.4, p. 457-473, jul 2013.

BROAD, ROBIN (Ed.) Global Backlash. Citizen Initiatives for a Just World Economy (Lanham, MD: Rowman \& Littlefield, 2002. Oferece uma visão geral do MJG, incluindo as suas raízes históricas.

\footnotetext{
${ }^{132}$ Baumgarten, 2013.
} 
BRAND, U. Contradictions and crises of neoliberal-imperial globalization and the political opportunity structures for the Global Justice Movements. Innovation: The European Journal of Social Science Research, v.25, n.3, p. 283-298, 2012.

BRINGEL, B. ; MUÑOZ , E. Dez anos de Seattle, o movimento antiglobalização e a ação coletiva transnacional. Ciências Sociais Unisinos, v. 46, n. 1, p. 28-36, 2010.

BROAD, R. Global Backlash. Citizen Initiatives for a Just World Economy. Lanham: Rowman \& Littlefield. $2002 a$.

BROAD, R. The Historical context. In BROAD, R. (Org.). Global Backlash: Citizen Initiatives for a Just World Economy. Lanham, MS: Rowman \& Littlefield, 2002b, p. 65-76.

BYRD, S. C.; JASNY, L. Transnational Movement Innovation and Collaboration: Analysis of World Social Forum Networks. In Smith, J.; Byrd, S.; Reese, E. ; Smythe, E. (Org.). Handbook on World Social Forum Activism. Boulder, CO: Paradigm Publishers, 2011, p. 355-372.

DELLA PORTA, D. (Org.) Democracy in Social Movements. Basingstoke: Palgrave Macmillan, 2009.

DELLA PORTA, DONATELLA (Ed.). Democracy in Social Movements. Basingstoke: Palgrave Macmillan, 2009. Dedicado à questão de como a democracia é praticada no MJG.

DELLA PORTA, D. The Social Bases of the Global Justive Movement. Some Theoretical reflections and Empirical Evidence from the First European Social Forum: New York UNRISD/UN Publications, 2005.

DOERR, N. Deliberative Discussion, Language, and Efficiency in the World Social Forum Porcess . Mobilization, v. 13, n. 4, p. 395-410, 2008.

FUSTER MORELL, M. The Free Culture and 15M Movements in Spain: Composition, Social Networks and Synergies. Social Movement Studies, v. 11, N. 3-4, p. 1-7, 2012.

GIUGNI, M.; BANDLER, M. ; EGGERT N. The Global Justice Movement. How Far Does the Classic Social Movement Agenda Go in Explaining Transnational Contention? United Nations Research Institute for Social Development, Civil Society and Social Movements Programme, Paper No. 24, Jun 2006.

GLASIUS, M.; TIMMS J. The Role of Social Forums in Global Civil Society. Radical Beacon or Strategic Infrastructure. In Glasius, M.; Kaldor, M.; Anheier H. (Org.) Global Civil Society 2005-2006. London: Sage, 2006, p. 208-226. 
GREEN, D. ; GRIFFITH M. Globalization and Its Discontents. International Affairs, v. 78, n. 1, p. 49-68, 2002.

Hayduk, R. Global Justice and OWS. Movement Connections. Socialism and Democracy, v. 26, n. 2, p. 43-50, 2012.

HECKSCHER, Z. Long before Seattle. Historical Resistance to Economic Globalization. In BROAD, R. (Org.) Global Backlash. Citizen Initiatives for a Just World Economy. Lanham: Rowman \& Littlefield, 2002, p. 86-91.

HESSEL, S. Time for outrage! New York: Twelve, 2011.

IBRAHIM, Y. Understanding the Alternative Globalisation Movement. Sociology Compass, V. 3, n. 3, p. 394-416, 2009.

KLEIN, N. Reclaiming the Commons. In Reydams L. (Org.) Global activism reader. New York: Continuum, 2011, p. 341-346.

LANGMAN, L. From Virtual Public Spheres to Global Justice: A Critical Theory of Internetworked Social Movements. Sociological Theory, v. 23, n. 1, p. 42-74, 2005.

MCADAM, D. Conceptual origins, current problems, future directions. In McAdam, D.; McCarthy, J.D.; Zald, M. N. (Org.) Comparative perspectives on social movements. Political Opportunities, Mobilizing Structures, and Cultural Framings. Cambridge: Cambridge Univ. Press, 1996, p. 23-40.

NISTAL, T. A. Antecedents, Achievements and Challenges of the Spanish 15M Movement. In TEJERINA, B.; PERRUGORRA I. From Social to Political. New Forms of Mobilization and Democratization. Bilbao: Bizkaia Aretoa, 2012, p. 74-88.

PACZYNSKA, A. (2008) Turtles, Puppets and Pink Ladies. The Global Justice Movement in a Post-9/11 World. Working Papers in Global Studies: No.1, August.

PIANTA, M.; SILVA, F. S.; ZOLA D. Global Civil Society Events. Parallel Summits, Social Fora, Global Days of Action Update. Disponível em: www.gcsknowledgebase.org/wpcontent/uploads/updateparallelsummit2004.pdf. Accesso em: 10 set. 2012.

PLEYERS, G. Alter-globalization. Becoming actors in the global age. Cambridge: Polity, 2010.

REITER, H. Participatory Traditions within the Global Justice Movement. In Della Porta, D. (Org.) Democracy in Social Movements. Basingstoke: Palgrave Macmillan, 2009, p. 44-72. 
REYDAMS LUC (Ed.) Global activism reader. New York: Continuum, 2009. Coleção sobre o ativismo global que cobre várias áreas do MJG: trabalho global, direitos humanos, direitos das mulheres, meio ambiente, paz, justiça social e democracia.

ROMANOS, E. (2013) Collective Learning Processes within Social Movements. Some Insights into the Spanish 15M/Indignados Movement. In FLESHER FOMINAYA, C.; COX, L. (Org.) Understanding European Movements. New Social Movements, Global Justice Struggles. New Yourk/ Oxford: Routhledge, p. 203-219.

RUCHT, D. Social Forums as Public Stage and Infrastructure of Global Justice Movements. In SMITH, J. ; BYRD, S.; REESE, E.; SMYTHE E. (Org.) Handbook on World Social Forum Activism. Boulder, CO: Paradigm Publishers, 2011, p. 11-28.

RUCHT, D.; TEUNE, S. Forms of Action of Global Justice Movement Groups. Do Conceptions and Practices of Democracy Matter? In Della Porta, D. (Org.) Democracy in Social Movements. Basingstoke: Palgrave Macmillan, 2009, p. 171-193.

SCERRI, A. The World Social Forum. Another World Might Be Possible. Social Movement Studies, i-first article, p. 1-10, 2012.

SMITH, J. Globalizing Resistance. The Battle of Seattle and the Future of Social Movements. Mobilization, v. 6, n. 1, p. 1-19, 2001.

SMITH, JACKIE; BYRD, SCOTT ; REESE, ELLEN; SMYTHE, ELIZABETH (Ed.) Handbook on World Social Forum Activism. Boulder (CO) : Paradigm Publishers, 2011. Oferece informação muito recente e detalhada sobre o Processo Fórum Social

SMITH, J. Social movements for global democracy. Baltimore: Johns Hopkins University Press, 2008.

SMITH, J. G. Creating Spaces for Global Democracy: The World Social Forum Process. In REYDAMS, L. (Org.) Global activism reader. New York: Continuum, 2011, p. 347-375.

SMITH, J. G.; BYRD, S.; REESE, E; SMYTHE, E. Introduction. In SMITH, J.; BYRD, S.; REESE, E.; SMYTHE E. (Org.) Handbook on World Social Forum Activism. Boulder, CO: Paradigm Publishers, 2011a, p. 1-7.

SMITH, J. G.; BYRD, S.; REESE, E; SMYTHE, E. Handbook on World Social Forum Activism. Boulder, CO: Paradigm Publishers, 2011b.

SMITH, J.; DOERR N. Democratic Innovation in the U.S. and European Social Forums. In SMITH, J.; BYRD, S.; REESE, E.; SMYTHE E. (Org.) Handbook on World Social Forum Activism. Boulder, CO: Paradigm Publishers, 2011a, p. 339-359. 
SMITH, P. J. and E. SMYTHE (In)Fertile Ground? Social Forum Activism in its Regional and Local Dimensions. In SMITH, J.; BYRD, S.; REESE, E.; SMYTHE E. (Org.) Handbook on World Social Forum Activism. Boulder, CO: Paradigm Publishers, 2011a, p. 29-49.

SMYTHE, E. Our World is not for Sale! The WSF Process and Transnational Resistance to International Trade Agreements. In SMITH, J.; BYRD, S.; REESE, E.; SMYTHE E. (Org.) Handbook on World Social Forum Activism. Boulder, CO: Paradigm Publishers, 2011a, p.

SNOW, D.; BENFORD, R. Ideology, Frame Resonance, and Participant Mobilization. In KLANDERMANS, B.; KRIESI, H.; TARROW, S. (Org.) From Structure to Action: Comparing Social Movement Research Across Cultures. International Social Movement Research. Volume 1. London: JAI Press, 1988, p. 197-217.

TEIVANEN, T. The World Social Forum and Global Democratisation. Learning from Porto Allegre. Third World Quarterly, v. 23, n. 4, p. 621-632, 2002.

TEJERINA, B. PERRUGORRA, I. Continuities and Discontinuities in Recent Social Mobilizations. From New Social Movements to the Alter-Global Mobilizations and the 15M. In TEJERINA, B.; PERRUGORRA I. (Org.) From Social to Political. New Forms of Mobilization and Democratization. Bilbao: Bizkaia Aretoa, 2012, p. 89-107.

Recebido em: 20/09/2013 Aprovado em: 31/10/2013

Universidade do Estado de Santa Catarina - UDESC Centro de Ciências Humanas e da Educação - FAED

Revista PerCursos Volume 14 - Número 27 - Ano 2013 revistapercursos@gmail.com 